\title{
Current Research in Pulsed Laser Deposition
}

\author{
Liviu Duta ${ }^{1, *(1)}$ and Andrei C. Popescu ${ }^{2}$ \\ 1 Lasers Department, National Institute for Lasers, Plasma, and Radiation Physics, 409 Atomistilor Street, \\ 077125 Magurele, Romania \\ 2 Center for Advanced Laser Technologies (CETAL), National Institute for Lasers, Plasma and Radiation \\ Physics, 077125 Magurele, Romania; andrei.popescu@inflpr.ro \\ * Correspondence: liviu.duta@inflpr.ro
}

Citation: Duta, L.; Popescu, A.C. Current Research in Pulsed Laser Deposition. Coatings 2021, 11, 274. https://doi.org/10.3390/coatings 11030274

Received: 19 February 2021

Accepted: 22 February 2021

Published: 26 February 2021

Publisher's Note: MDPI stays neutral with regard to jurisdictional claims in published maps and institutional affiliations.

Copyright: (C) 2021 by the authors. Licensee MDPI, Basel, Switzerland. This article is an open access article distributed under the terms and conditions of the Creative Commons Attribution (CC BY) license (https:// creativecommons.org/licenses/by/ $4.0 /)$.
In industry, thin films proved invaluable for protection of tools withstanding high frictions and elevated temperatures, but also found successful applications as sensors, solar cells, bioactive coatings for implants, photocatalysis and in lithography. Other envisaged applications are currently researched for energy-storage devices, drug delivery or in situ microstructuring for enhancing the surface properties.

When compared to other plasma-assisted deposition methods, such as plasma spraying or plasma enhanced chemical vapor deposition, the Pulsed Laser Deposition (PLD) technique stands as a simple, versatile, rapid, and cost-effective approach for the fabrication of high-quality structures from a wide range of materials [1,2]. PLD as a thin film synthesis method, although limited in terms of surface covered area, still gathers interest among researchers due to some important advantages such as stoichiometric transfer of the target composition to the synthesized coatings, high adherence of the deposited structures to the substrate, improved uniformity in terms of morphology and chemical composition, controlled degree of phase, crystallinity, and thickness of deposited coatings, lower porosity, decreased tendency of the deposited structures to crack or delaminate, and relatively simple experimental set-up.

Over the last years, an increasing research interest was observed in the field of PLD synthesis of oxides and nitrides. From the first class, transparent conductive oxides, with indium tin oxide (ITO) as one of the most representative materials, were intensively investigated due to their applications in many technological areas, including sensors [3,4]. By combining UV nanoimprint lithography and PLD, the fabrication of nanopatterned ITO films was demonstrated to be appropriate for applications in the field of organic photovoltaic cells or organic light emitting devices. In addition, iron oxide $\left(\mathrm{Fe}_{2} \mathrm{O}_{3}\right)$ nanostructures have been also studied due to their unique electrical and magnetic properties, corroborated with the preservation of their chemical compatibility with biological tissues for various medical applications. Thus, the formation of iron oxide nanostructures was demonstrated using combined infrared pulsed laser ablation and carbothermal heat treatment of Fe microspheres [5]. It was shown that iron oxide nanowires and nanoflakes could be synthesized without the necessity of a catalyst. A possible growth mechanism of iron oxide nanowires was introduced considering both the $\mathrm{Fe}_{3} \mathrm{O}_{4} / \mathrm{Fe}_{2} \mathrm{O}_{3}$ interface and the chemical driving force for the diffusion of Fe species through the microsphere, which are kinetically and thermodynamically controlled by the amount of Fe and carbon gaseous species. An important aspect that should be mentioned is related to the targets' preparation for PLD synthesis of iron-doped indium oxide films. Therefore, at low oxygen pressures, it was shown that, besides the existence of iron ions in the $\mathrm{Fe}^{2+}$ state, rather than the $\mathrm{Fe}^{3+}$ one, there was little metallic iron. All these characteristics were followed by an important magnetization. When increasing the oxygen amount, the band gap increased also, whilst the number of defect phases and the saturation magnetization decreased. It was demonstrated that the oxygen amount in the target due to the precursor was an important factor 
but not a defining one for the overall quality of the films. It was also indicated that $\mathrm{FeO}$, in comparison to $\mathrm{Fe}_{2} \mathrm{O}_{3}$, could be a better choice due to a higher magnetization.

It should be emphasized that thin though hard coatings demonstrated to be of keyimportance for the fabrication of mechanical parts or tools due to their hardness and wear-resistance characteristics [6]. Therefore, nitride-based films were recently investigated as protective coatings, due to their physical-chemical, electronic, thermal, or mechanical properties [7-10]. Particularly, aluminum nitride coatings own such characteristics, which qualify them as relevant candidates for a wide range of applications, including photodetectors, light-emitting and laser diodes, acoustic devices, insulating and buffer layers, or designs of self-sustainable opto- and micro-electronical devices [11-13].

Solid-electrolyte thin-films are mainly fabricated by thermal vacuum evaporation and radiofrequency-sputtering techniques. It is important to note that their synthesis by the PLD method generated improvements in their intrinsic characteristics. Due to an increasing demand for smaller power sources, the current interest in rechargeable microbatteries has expanded. Therefore, the recent progress in the field of lithium microbatteries is quite remarkable, and this is mainly due to the PLD growth of high-quality, pinhole-free, solidstate electrolyte thin films (i.e., $\mathrm{Li}_{6.1} \mathrm{~V}_{0.61} \mathrm{Si}_{0.39} \mathrm{O}_{5.36}$ ). In this respect, using the sequential PLD technique, rechargeable thin-film lithium-ion batteries were designed [14].

Aiming to expand the field of hard tissue engineering and regeneration, many biomaterials were designed and exploited in different strategies, either for controlled drug delivery [15], or to address various bone-related traumas [16]. For this aim, Matrix-Assisted Pulsed Laser Evaporation (MAPLE), which is a variation of the PLD technique, was recently used to deposit thin films of shellac for targeted drug release [17]. Thus, it was demonstrated that the laser fluence is a key parameter in preserving the chemical structure of shellac. In the case of low fluences, all the characteristic absorption bands were shown and the best concordance to the pristine shellac was indicated. One innovative approach to boost the efficiency of a biomaterial could be to coat it with a natural protein or a biologicalderived compound. To the difference of injecting a bioactive compound, which has the disadvantage of a rapid removal from the living body, the deposition of a protein onto the surface of the implanted material can determine an increase in its concentration, which further results in a controlled local release. Post-surgical infections in bone implants could be therefore prevented [18], and a local induction of osteogenic differentiation can be also favored [15]. In this respect, lactoferrin (Lf) is a protein of interest, due to its antimicrobial and anticarcinogenic activities, corroborated with an anti-inflammatory function and an osteogenic role $[19,20]$. Thus, it was demonstrated that the controlled release of the components by polymeric coating could better accommodate the combination of the properties of both biological compounds, (i.e., the bone mechanical stability and osteogenic capacity of hydroxyapatite, HA) with the anti-inflammatory and osteogenic effect of the Lf component, which make the composition an excellent support for further bone regeneration.

Calcium phosphates (CaP) are the main inorganic component of bone tissues [21]. Due to their excellent biocompatibility, high adherence to the substrate, and osseointegration and osteoconduction characteristics, CaP-based bioceramic materials are widely used in the domain of bone regeneration, both in orthopedics and dentistry [22-25], mainly as coatings for metallic implants [26]. In the last few decades, research focus was put on HA, which represents the most frequently used $\mathrm{CaP}$ due to some important properties, like its role as a scaffold for osteogenic differentiation [27] and its capacity to stimulate and accelerate the formation of new bone around implants [28,29]. The advantages of using animal-origin HA (BioHA) coatings, fabricated by the PLD technique, as viable alternatives to synthetic HA ones for various medical applications, were recently emphasized [16]. In this respect, the biocompatibility of BioHA materials was reported to be superior to that of synthetic HA, with respect to cells' morphology, proliferation, and bioactivity [16]. Moreover, when doped with various agents (i.e., $\mathrm{Ti}_{\text {or }} \mathrm{Li}_{2} \mathrm{CO}_{3}$ ), the effect was an increase in cell proliferation $[30,31]$. Therefore, animal-origin HA could represent a reliable, promising, safe, and, most importantly, low-cost resource for coatings that aim for biomimetism. For 
PLD, this domain is still in his incipient stage of development, offering endless possibilities for expansion in terms of natural-CaP new resources, various concentrations of doping elements, or controlled degree of the obtained coatings' morphology and structure. It was also demonstrated that, to the difference of synthetic HA, BioHA coatings could exhibit antimicrobial properties, besides an increased bioactivity. One could therefore conclude that, the future of biomimetic coatings might belong mainly to the natural-origin CaPs source materials, and their stoichiometric transfer and delicate tailoring in terms of thickness, crystallinity, and functional groups can be performed by PLD as an optimal deposition method. In addition, two decades of achievements focused on the in vivo performances of CaP-based coatings fabricated by the PLD technique were also reported [32]. One should note that, in the dedicated literature, there are studies on the in vivo testing of CaP-based coatings (especially HA) synthesized by numerous physical vapor deposition methods, but only few of them addressed the PLD technique. It was demonstrated that the values inferred from the mechanical tests (concerning bone attachment) were all superior for the functionalized Ti implants as compared to simple Ti ones. Both the PLD surface functionalization of metallic implants and a longer implantation time period were shown to have a key role on the overall bone bonding strength characteristics of the investigated medical devices. Despite the interesting progress made in vitro and in vivo in the field of CaP-coated metallic implants by PLD, not enough comparable clinical results were delivered so far for an easier assessment. This was mainly because of the lack of standardization of the coating properties and in vivo models. As a consequence, additional tests are still needed to be performed, both to advance a certain "recipe" for optimum in vivo results, and to evidence the relative influence of implant design, surgical procedure, and coating characteristics (thickness and surface structure and morphology), on the short- and long-term characteristics of the CaP-based synthesized structures.

Taking into consideration all these facts, one can conclude that a leap forward for PLD, which is mainly a laboratory technique, could be its recognition as an industrial coating technique in the near future. This is now more achievable than ever due to progress in robotics, which can help with automatic and precise translation of targets and substrates, but also to advances in vacuum techniques, allowing for generation of a high vacuum in large enclosed spaces.

Author Contributions: Writing—original draft preparation, L.D.; writing—review and editing, L.D. and A.C.P. All authors have read and agreed to the published version of the manuscript.

Funding: L.D. acknowledges the support from two grants of Ministry of Research and Innovation, CNCS-UEFISCDI, PN-III-P1-1.1-PD-2016-1568 (PD 6/2018) and PN-III-P1-1.1-TE2019-1449 (TE189/2021), and the Romanian Ministry of Education and Research, under Romanian National Nucleus Program LAPLAS VI-Contract 16N/2019.

Acknowledgments: The Guest Editors, L.D. and A.C.P., thank to all the authors for their contributions to this Special Issue "Current Research in Pulsed Laser Deposition" and to the editorial staff of the journal Coatings.

Conflicts of Interest: The authors declare no conflict of interest.

\section{References}

1. Chrisey, D.B.; Hubler, G.K. Pulsed Laser Deposition of Thin Films, 1st ed.; John Wiley \& Sons: Hoboken, NJ, USA, 1994.

2. Eason, R. Pulsed Laser Deposition of Thin Films-Applications-Led Growth of Functional Materials; Wiley-Interscience: Hoboken, NJ, USA, 2006

3. Socol, M.; Preda, N.; Rasoga, O.; Costas, A.; Stanculescu, A.; Breazu, C.; Gherendi, F.; Socol, G. Pulsed Laser Deposition of Indium Tin Oxide Thin Films on Nanopatterned Glass Substrates. Coatings 2019, 9, 19. [CrossRef]

4. Albargi, H.B.; Alshammari, M.S.; Museery, K.Y.; Heald, S.M.; Jiang, F.X.; Saeedi, A.M.A.; Fox, A.M.; Gehring, G.A. Relevance of the Preparation of the Target for PLD on the Magnetic Properties of Films of Iron-Doped Indium Oxide. Coatings 2019, 9, 381. [CrossRef] 
5. De Vero, J.C.; Jasmin, A.C.; Dasallas, L.L.; Garcia, W.O.; Sarmago, R.V. Synthesis of Iron Oxide Nanostructures via Carbothermal Reaction of Fe Microspheres Generated by Infrared Pulsed Laser Ablation. Coatings 2019, 9, 179. [CrossRef]

6. Kolaklieva, L.; Chitanov, V.; Szekeres, A.; Antonova, K.; Terziyska, P.; Fogarassy, Z.; Petrik, P.; Mihailescu, I.N.; Duta, L. Pulsed Laser Deposition of Aluminum Nitride Films: Correlation between Mechanical, Optical, and Structural Properties. Coatings 2019, 9, 195. [CrossRef]

7. Jianxin, D.; Aihua, L. Dry sliding wear behavior of PVD TiN, Ti55Al45N, and Ti35Al65N coatings at temperatures up to $600{ }^{\circ} \mathrm{C}$. Int. J. Refract. Met. Hard Mater. 2013, 41, 241-249. [CrossRef]

8. Jianxin, D.; Fengfang, W.; Yunsong, L.; Youqiang, X.; Shipeng, L. Erosion wear of CrN, TiN, CrAlN, and TiAlN PVD nitride coatings. Int. J. Refract. Met. Hard Mater. 2012, 35, 10-16. [CrossRef]

9. Liang, C.L.; Cheng, G.A.; Zheng, R.T.; Liu, H.P. Fabrication and performance of TiN/TiAlN nanometer modulated coatings. Thin Solid Films 2011, 520, 813-817. [CrossRef]

10. Cecchini, R.; Fabrizi, A.; Cabibbo, M.; Paternoster, C.; Mavrin, B.N.; Denisov, V.N.; Novikova, N.N.; Haïdopoulo, M. Mechanical, microstructural and oxidation properties of reactively sputtered thin CrN coatings on steel. Thin Solid Films 2011, 519, 6515-6521. [CrossRef]

11. Duta, L.; Stan, G.E.; Stroescu, H.; Gartner, M.; Anastasescu, M.; Fogarassy, Z.; Mihailescu, N.; Szekeres, A.; Bakalova, S.; Mihailescu, I.N. Multi-stage pulsed laser deposition of aluminum nitride at different Temperatures. Appl. Surf. Sci. 2016, 374, 143-150. [CrossRef]

12. Antonova, K.; Duta, L.; Szekeres, A.; Stan, G.E.; Mihailescu, I.N.; Anastasescu, M.; Stroescu, H.; Gartner, M. Influence of laser pulse frequency on the microstructure of aluminum nitride thin films synthesized by pulsed laser deposition. Appl. Surf. Sci. 2017, 394, 197-204. [CrossRef]

13. Fogarassy, Z.; Petrik, P.; Duta, L.; Mihailescu, I.N.; Anastasescu, M.; Gartner, M.; Antonova, K.; Szekeres, A. TEM and AFM studies of aluminium nitride films synthesized by pulsed laser deposition. Appl. Phys. A 2017, 123, 756. [CrossRef]

14. Julien, M.C.; Mauger, A. Pulsed Laser Deposited Films for Microbatteries. Coatings 2019, 9, 386. [CrossRef]

15. Icriverzi, M.; Rusen, L.; Brajnicov, S.; Bonciu, A.; Dinescu, M.; Cimpean, A.; Evans, R.W.; Dinca, V.; Roseanu, A. Macrophage in vitro Response on Hybrid Coatings Obtained by Matrix Assisted Pulsed Laser Evaporation. Coatings 2019, 9, 236. [CrossRef]

16. Duta, L.; Popescu, A.C. Current Status on Pulsed Laser Deposition of Coatings from Animal-Origin Calcium Phosphate Sources Coatings 2019, 9, 335. [CrossRef]

17. Brajnicov, S.; Bercea, A.; Marascu, V.; Matei, A.; Mitu, B. Shellac Thin Films Obtained by Matrix-Assisted Pulsed Laser Evaporation (MAPLE). Coatings 2018, 8, 275. [CrossRef]

18. Nagano-Takebe, F.; Miyakawa, H.; Nakazawa, F.; Endo, K. Inhibition of initial bacterial adhesion on titanium surfaces by lactoferrin coating. Biointerphases 2014, 9, 029006. [CrossRef] [PubMed]

19. Moreno-Exposito, L.; Illescas-Montes, R.; Melguizo-Rodriguez, L.; Ruiz, C.; Ramos-Torrecillas, J.; de Luna-Bertos, E. Multifunctional capacity and therapeutic potential of lactoferrin. Life Sci. 2018, 195, 61-64. [CrossRef] [PubMed]

20. Garcia-Montoya, I.A.; Cendon, T.S.; Arevalo-Gallegos, S.; Rascon-Cruz, Q. Lactoferrin a multiple bioactive protein: An overview. BBA Gen. Subj. 2012, 1820, 226-236. [CrossRef] [PubMed]

21. Eliaz, N.; Metoki, N. Calcium Phosphate Bioceramics: A Review of Their History, Structure, Properties, Coating Technologies and Biomedical Applications. Materials 2017, 10, 334. [CrossRef]

22. Oladele, I.O.; Agbabiaka, O.; Olasunkanmi, O.G.; Balogun, A.O.; Popoola, M.O. Non-synthetic sources for the development of hydroxyapatite. J. Appl. Biotechnol. Bioeng. 2018, 5, 88-95. [CrossRef]

23. Akram, M.; Ahmed, R.; Shakir, I.; Ibrahim, W.A.W.; Hussain, R. Extracting hydroxyapatite and its precursors from natural resources. J. Mater. Sci. 2014, 49, 1461-1475. [CrossRef]

24. Šupová, M. Substituted hydroxyapatites for biomedical applications: A review. Ceram. Int. 2015, 41, 9203-9231. [CrossRef]

25. Graziani, G.; Boi, M.; Bianchi, M. A Review on Ionic Substitutions in Hydroxyapatite Thin Films: Towards Complete Biomimetism. Coatings 2018, 8, 269. [CrossRef]

26. Tite, T.; Popa, A.C.; Balescu, L.M.; Bogdan, I.M.; Pasuk, I.; Ferreira, J.M.F.; Stan, G.E. Cationic substitutions in hydroxyapatite: Current status of the derived biofunctional effects and their in vitro interrogation methods. Materials 2018, 11, 2081. [CrossRef] [PubMed]

27. Ballini, A.; Mastrangelo, F.; Gastaldi, G.; Tettamanti, L.; Bukvic, N.; Cantore, S.; Cocco, T.; Saini, R.; Desiate, A.; Gherlone, E.; et al. Osteogenic differentiation and gene expression of dental pulp stem cells under low-level laser irradiation: A good promise for tissue engineering. J. Biol. Regul. Homeost. Agents 2015, 29, 813-822. [CrossRef] [PubMed]

28. Surmenev, R.A.; Surmeneva, M.A. A critical review of decades of research on calcium phosphate-based coatings: How far are we from their widespread clinical application? Curr. Opin. Biomed. Eng. 2019, 10, 35-44. [CrossRef]

29. Dorozhkin, S.V. Biphasic, triphasic, and multiphasic calcium orthophosphates. In Advanced Ceramic Materials; Tiwari, A., Gerhardt, R.A., Szutkowska, M., Eds.; Wiley, Scrivener Publishing: Austin, TX, USA, 2016; pp. 33-95.

30. Popescu, A.C.; Florian, P.E.; Stan, G.E.; Popescu-Pelin, G.; Zgura, I.; Enculescu, M.; Oktar, F.N.; Trusca, R.; Sima, L.E.; Roseanu, A.; et al. Physical-chemical characterization and biological assessment of simple and lithium-doped biological-derived hydroxyapatite thin films for a new generation of metallic implants. Appl. Surf. Sci. 2018, 439, 724-735. [CrossRef] 
31. Duta, L.; Mihailescu, N.; Popescu, A.C.; Luculescu, C.R.; Mihailescu, I.N.; Cetin, G.; Gunduz, O.; Oktar, F.N.; Popa, A.C.; Kuncser, A.; et al. Comparative physical, chemical and biological assessment of simple and titanium-doped ovine dentinederived hydroxyapatite coatings fabricated by pulsed laser deposition. Appl. Surf. Sci. 2017, 413, 129-139. [CrossRef]

32. Duta, L. In Vivo Assessment of Synthetic and Biological-Derived Calcium Phosphate-Based Coatings Fabricated by Pulsed Laser Deposition: A Review. Coatings 2021, 11, 99. [CrossRef] 